\title{
Imagens de Paris: a fantasmagoria benjaminiana e as Mitologias de Roland Barthes
}

\author{
Images of Paris: Benjamin's phantasmagoria and Mythologies by Roland \\ Barthes
}

Lara Luiza Spagnol Oliveira
UFMG

\begin{abstract}
Resumo: Este artigo destina-se a aproximar a noção de fantasmagoria proposta por Walter Benjamin, à noção de mito enquanto um sistema semiológico, proposta por Roland Barthes. Para tanto, consultou-se o Exposé benjaminiano de 1939, intitulado "Paris, Capital do Século XIX”, e as Mitologias, obra lançada em 1957 por Barthes. O objetivo de aproximar tais obras é mostrar como ambas observações realizadas a respeito da sociedade parisiense, em contextos distintos, são capazes de chegar à conclusões análogas a respeito de termos como a modernidade, o capitalismo e a sociedade de consumo, tal qual a relação ilusória existente entre a significação dos objetos de consumo e o consumidor.
\end{abstract}

Palavras-chave: Walter Benjamin; Roland Barthes; fantasmagoria; mito; modernidade; espaço urbano.

Abstract: This article is intended to approximate the notion of phantasmagoria proposed by Walter Benjamin, to the notion of myth while a semiotic system, proposed by Roland Barthes. For this purpose, the Benjamins's 1939 Exposé, "Paris, Capital of the Nineteenth Century", was researched, as the "Mythologies", released in 1957 by Barthes. The aim of bringing such works is to show how both impressions of the Parisian society, even in different contexts, are able to come to similar conclusions regarding terms such as modernity, capitalism and the consumer society, such as the illusory relations existing between the significance of consumer goods and the consumer.

Key-Words: Walter Benjamin; Roland Barthes; phantasmagoria; myth; modernity; urban space.

\section{A fantasmagoria na capital do século XIX}

Em 1939, Walter Benjamin reedita um Exposé escrito em 1935, atribuindo a ele uma introdução e algumas modificações, e nomeia-o, então, como Paris, Capital do Século XIX. No título escolhido para suas reflexões, está apresentada a centralidade desta cidade no estudo benjaminiano sobre a modernidade: Paris não é só capital de um país, ela é capital de um século inteiro, é a representante de um período.

É justamente com a chegada da modernidade, entre o fim do século XIX e o início do século XX, que as grandes metrópoles urbanas passam por um processo de renovação do crescimento anteriormente experimentado durante o período industrial. $O$ interesse, nesse momento, é o de revitalizar os espaços urbanos de acordo com as necessidades de uma sociedade que agora é regida pelos ideais do progresso e, sobretudo, pelos ideais do consumo. Em Paris, Capital do século XIX (Exposé de 1939), Walter Benjamin (2006) irá discorrer sobre os reflexos desse desenvolvimento capitalista e da centralização da mercadoria em Paris. A modernidade, então, será lida em Benjamin a partir da observação da consolidação 
das metrópoles do período moderno. Em um amplo aspecto, a reflexão principiada no Exposé anteriormente mencionado é o cerne do que comporá o maior projeto benjaminiano: a obra das Passagens (BENJAMIN, 2006), que, segundo Willi Bolle, responsável pelo prefácio da edição brasileira, constrói uma montagem surrealista da cidade através de imagens dialéticas. Citando:

O livro sobre Paris, conhecido como a Obra das Passagens e elaborado no exílio durante a época do nazismo, procura, segundo o autor, apresentar "as experiências que todos nós fizemos durante os últimos quinze anos" [1923 - 1938]; é uma tentativa de compreender o tipo de mentalidade responsável pela passagem da república para a ditadura, focando como protagonistas "as massas". (BOLLE, 1994, p. 17)

A cidade de Paris parece exercer um fascínio sobre o pensamento de Walter Benjamin, a julgar por sua presença central naquela que é tida como uma de suas mais importantes obras.

Abrindo aqui um pequeno parêntese, penso ser interessante trazer o comentário que, em Homens em Tempos Sombrios, Hannah Arendt (1999) realiza sobre o interesse de Benjamin pelos detalhes, pelas coisas em miniatura:

\footnotetext{
Benjamin tinha paixão pelas coisas pequenas, até minúsculas: [...] Para ele, a dimensão de um objeto era inversamente proporcional à sua significação. E essa paixão, longe de ser um capricho, derivava diretamente da única concepção de mundo que teve uma influência decisiva sobre ele, a convicção de Goethe sobre a existência fática de um Urphänomen, um fenômeno arquetípico, uma coisa concreta a ser descoberta no mundo das aparências, na qual coincidiriam significado [...] e aparência, palavra e coisa, idéia e experiência. (ARENDT, 199, p. 142)
}

A observação de Arendt sobre a obsessão de Benjamin pelos detalhes talvez nos ajude a entender o método existente em obras como as Passagens, que se propõe a ir da potência de significação contida no menor objeto até a reflexão sobre todo um século, pois é fato que encontraremos aí um esquadrinhar da cidade de Paris em suas menores e mais significativas representações.

É através dessa metrópole, portanto, que Walter Benjamin irá focalizar as mudanças, os fenômenos, os efeitos da modernidade que as sociedades que encontram-se neste período de transição experimentam. Em seu Exposé, Benjamin almeja mostrar como as inovações tecnológicas e econômicas do século XIX resultaram em uma "representação coisificada da civilização" (2006, p. 53), que faz com que as expressões sociais e culturais, as formas de vida da modernidade, enfim, estejam imersas em um universo de Fantasmagorias. Sendo assim, a arquitetura das Passagens, o entretenimento prometido pelas Exposições Universais, o universo particular do burguês, o flâneur enquanto figura limiar deste período, a modernização das ruas de Paris, todos estes elementos serão observados a partir de suas manifestações enquanto fantasmagorias.

O termo escolhido por Benjamin relembra os espetáculos das fantasmagorias, populares em Paris durante o século XIX, em que projetores, luzes, fumaças e sons eram manipulados a fim de criar figuras fantasmagóricas e amedrontar o público. A alusão ao termo, naturalmente, não é gratuita: assim como os falsos fantasmas gerados para entretenimento dos espectadores, a sociedade de consumo produziria suas próprias imagens de ilusão para seduzir os indivíduos que a ela pertencem. A mercadoria, alçada ao posto de objeto de admiração e em torno do qual se reúne a população não só metaforicamente, mas 
também literalmente, como Benjamin demonstra ser o caso das Exposições Universais, passa a ser o centro em torno do qual orbita a sociedade de consumo. O autor afirma, em Paris, Capital do Século XIX:

\begin{abstract}
As exposições universais são os centros de peregrinação ao fetiche mercadoria. 'A Europa se deslocou para ver mercadorias', afirma Taine, em 1855. [...] Os trabalhadores formarão a primeira clientela. O quadro da indústria de entretenimento ainda não se constituíra. Este quadro, é a festa popular que o fornece. [...] As exposições universais idealizam o valor de troca das mercadorias. Criam um quadro no qual seu valor de uso passa a segundo plano. As exposições universais constituíram uma escola onde as multidões, forçosamente afastadas do consumo, se imbuíram do valor de troca das mercadorias a ponto de se identificarem com ele. [...] Assim, elas dão acesso a uma fantasmagoria onde o homem entra para se deixar distrair. (BENJAMIN, 2006, p. 57.)
\end{abstract}

Está aí contida a noção de que essa sociedade que produz mercadorias, produz simultaneamente uma imagem de si mesma que oculta a lembrança de como tais mercadorias teriam surgido - ou seja, a lembrança de quem as teria produzido e de que modo. A mercadoria e as manifestações dessa cultura de consumo são, então, fantasmagorias, pois funcionam como uma ilusão e ao mesmo tempo como um disfarce de uma realidade gerida por uma produção retroalimentada: a mercadoria é feita pelos operários, para o desejo e o consequente consumo desses mesmos operários. A fantasmagoria seria resultante de uma sociedade regida pela produção e pelo consumo de mercadorias; é ela quem, neste contexto, media de forma ilusória a relação entre indivíduo e coisa.

Essa noção de fantasmagoria é essencial para pensarmos a Paris do período moderno pois ela desloca um dos aspectos básicos da modernidade: o choque da tradição com o novo. Se as fantasmagorias funcionam como uma ilusão que separa os métodos de produção da mercadoria do encantamento que a mercadoria exerce sobre os indivíduos da sociedade de consumo - e aqui, noções como a do fetiche marxista podem ajudar a pensar sobre tal questão -, podemos pensar na sociedade europeia moderna, da qual Paris seria exemplo, como uma sociedade que vive a principal ilusão da modernidade, ou seja, a ilusão do novo. Modernizar uma sociedade significa também romper com suas tradições, e buscar a inovação. Como Benjamin propõe, porém, ao comentar principalmente a haussmannização de Paris, na qual "a fantasmagoria se fez pedra" (2006, p. 64.), esses impulsos inovadores mostram sua ineficiência e seu caráter ilusório quando revelam não serem capazes de promover uma mudança real na sociedade. Haussman expropria os habitantes parisienses de suas casas, transformando o centro de Paris em um espaço urbano sem identidade. Seu impulso modificador intenciona proteger Paris de uma "eventual guerra civil" (BENJAMIN, 2006, p. 64), alargando suas ruas para impedir a construção de barricadas. Porém, como lembra Benjamin, a queda do Segundo Império e a Comuna de Paris vêm para mostrar que a inovação não representa, necessariamente, uma mudança estrutural: a inovação do período moderno só existiria, então, como todos os outros elementos da cultura da sociedade mercadológica - enquanto fantasmagoria.

\title{
20 mito como sistema semiológico
}

Entre 1954 e 1956, alguns anos após Walter Benjamin ter escrito suas considerações sobre Paris e o século XIX, Roland Barthes escreve um conjunto de textos ao qual denomina 
Mitologias. Nesses textos, o crítico francês realizará o que denominou de uma desmontagem semiológica da cultura de massa francesa presente durante os anos 50. Nas palavras do próprio autor, que compõem a introdução dessa obra, estão contidos suas motivações e objetivos ao iniciar tal empreitada:

Os textos que se seguem foram escritos mês após mês aproximadamente durante dois anos, de 1954 a 1956, ao sabor da atualidade. Tentava então refletir regularmente sobre alguns mitos da vida cotidiana francesa. $\mathrm{O}$ material desta reflexão veio a ser muito variado (um artigo de jornal, uma fotografia de semanário, um filme, um espetáculo, uma exposição) e o assunto muito arbitrário: tratava-se evidentemente da minha atualidade. (BARTHES, 1972, p. 7).

O impulso da catalogação de tais mitos parece advir da afirmação de Barthes de que a imprensa, a arte e o senso comum tomariam a realidade sobre a máscara do natural - daquilo que é forçosamente naturalizado. $\mathrm{O}$ desmonte das cadeias semiológicas presentes nos objetos culturais da vida francesa (como os combates de catch, brinquedos infantis e até propagandas de sabão e margarina) leva, então, ao fim da obra, a uma definição do que seria o mito contemporâneo para Barthes. O que chama-nos a atenção aqui, é o fato de que as Mitologias, de Roland Barthes, de algumas formas, permitem-nos ler as fantasmagorias, de Walter Benjamin, enquanto um mito da modernidade. Para além disso, há ainda uma semelhança de método (ainda que seja difícil pensar em um método benjaminiano de análise ou de estudo) entre os dois autores: se Benjamin debruça-se sobre os aspectos cotidianos da Paris do século XIX (as Passagens, o Flâneur, as Exposições Universais, as ruas da cidade), Barthes fará o mesmo com a sociedade francesa da década de 50, e irá lê-la em seus produtos culturais. Por fim, a conclusão a que ambos chegam também se assemelha de alguma forma, como vamos acompanhar adiante: se Benjamin vê as manifestações culturais, políticas e sociais da Paris moderna como infiltradas em um universo de uma fantasmagoria, Barthes observa na sociedade francesa a tentativa de "naturalizar" a realidade. Em ambos os casos, então, existe uma mediação entre indivíduo e coisa que funciona como um véu que distorce a realidade. Barthes entenderá o mito justamente como esta linguagem deformadora do real.

Para realizar as aproximações mencionadas, é necessário entender a partir de qual abordagem Barthes focaliza o mito em sua obra. Primeiramente, o autor afirma que "o mito é uma fala, uma mensagem, um modo de significação, uma forma". (BARTHES, 1993, p. 131), mas que, naturalmente, não é uma fala qualquer" (BARTHES, 1993, p. 131). Essa fala (ou essa mensagem), porém, é definida não por seu objeto, mas pela forma como profere esse objeto. "O mito tem limites formais, mas não substanciais" (BARTHES, 1993, p. 131), afirma. O mito é, portanto, uma questão de forma, e como tal, será pensado na obra barthesiana a partir do viés da semiologia. Na tentativa de compreender a noção de mito abordada nessa obra, é necessário realizar aqui um breve desvio para o campo da semiologia.

$\mathrm{Na}$ definição barthesiana, "a semiologia é uma ciência das formas, visto que estuda as significações independentemente do seu conteúdo" (1993, p. 133). Na definição de um sistema semiológico, Barthes relembra a relação entre o significante e o significado, que, associados, são representados pelo signo (o autor usa, especificamente, a expressão "total associativo" (BARTHES, 1993, p. 135) entre os dois primeiros termos, na definição do signo dentro da triangulação semiológica). A partir deste viés, portanto, Barthes entenderá o mito como "um sistema semiológico segundo" (1993, p. 137), no qual a triangulação significante, significado e signo traz, em seu próprio significante, um sistema semiológico anterior.

A este sistema anterior, Barthes dá o nome de linguagem-objeto, e nele está contido um sistema semiológico próprio, relativo à linguagem que será, em um segundo momento, utilizada pelo mito - este denominado como metalinguagem. O sistema semiológico em que se encontra o mito, então, é composto por termos de certa forma análogos aos termos usuais da semiologia. Porém, devido ao fato de o mito engendrar um sistema distinto, Barthes utiliza 
outros termos nessa definição. Sendo assim, no sistema do mito, a forma (correspondente ao significante, que, neste caso, contém em si outro sistema semiológico, ou seja, a linguagem), juntamente ao conceito (correspondente ao significado), dá origem a uma significação (análoga ao signo). A utilização da forma na semiologia do mito opera um processo de esvaziamento de sentidos prévios. Isto porque, como comentado, a forma, no mito, corresponde a um sistema de linguagem anterior, previamente existente, o qual possui uma significação primeira. Ao ser inserido na semiologia do mito, esse sentido pré-existente assume lugar de forma (vazia de sentido), à qual outro significado será atribuído. O mito, então, opera a partir da supressão e do aparecimento do sentido anterior dessa forma.

\section{3 "O escritor em férias": uma mitologia parisiense}

Quando Barthes propõe observar o mito através de uma perspectiva semiológica, acreditamos que estejam sendo desconstruídas, por intermédio desse processo, as noções usuais de mito, que tangenciam as histórias, lendas e cosmogonias dos povos, ou que se propõem como a oposição à verdade e à racionalidade. Ao contrário disso, o mito barthesiano foca-se no esvaziamento de um sentido anterior para a consequente atribuição de uma ressignificação.

É interessante o processo de esvaziamento e ressignificação (de mitificação, portanto) que Barthes expõe ao comentar a série "O escritor em férias", produzida pelo jornal francês Fígaro, sobre a qual ele escreve "Gide lia Bossuet descendo o Congo. Esta postura resume bem o ideal de nossos escritores "em férias", fotografados pelo Fígaro: juntar ao lazer normal, o prestígio de uma vocação que nada pode suster ou degradar.” (1993, p. 23). A afirmação de Barthes, ao analisar tal série, é a de que, ao retirar da imagem do escritor sua primeira significação (a do escritor como um intelectual convicto, talvez até irreparável, que está constantemente exercendo sua função), a série tenta ressignificá-lo a partir de outro sentido, mostrando-o como alguém que também descansa de sua profissão: inserido na lógica capitalista, o escritor também precisa de férias do seu trabalho, e goza delas fazendo as coisas o mais usuais possível. A série quer promover, então, o escritor como um trabalhador, como tantos outros indivíduos parisienses.

O que Barthes lê, porém, através do processo semiológico através do qual o mito ressignifica o escritor, é o fato de que naturalizá-lo, é, ainda, alça-lo a um posto de indivíduo ainda mais distinto. Em suas palavras:

\footnotetext{
Atribuir publicamente ao escritor um corpo bem carnal, revelar que ele gosta de vinho branco seco e do filé mal passado, equivale a tornar a nossos olhos os produtos de sua arte ainda mais milagrosos e de essência mais divina. Os detalhes da sua vida cotidiana não só não aproximam nem esclarecem a natureza da sua inspiração, mas, muito pelo contrário, é a singularidade mítica da sua condição que o escritor acusa nessas confidências. (BARTHES,1993, p. 25)
}

O sistema mitológico, então, tenta esvaziar o escritor de seu significado anterior, deixando para ele uma forma, vazia de conteúdo, na qual outros significados podem ser imputados. Barthes, porém, desconstrói este sistema mitológico e questiona os significados que tentam ser imputados para a figura do escritor, ao revelar a indagação que resta após esse processo: como poderia, o escritor, ser ao mesmo tempo um sujeito tão comum, e tão brilhante? 


\section{A fantasmagoria como mito}

A dinâmica mítica que Barthes delineia ao analisar os objetos culturais da Paris que lhe é contemporânea também parece ser a dinâmica através da qual a fantasmagoria envolve a sociedade da Paris sobre a qual Benjamin debruça-se. Utilizando o exemplo das Exposições Universais, anteriormente mencionadas, pensemos, inicialmente, em seu principal atrativo: as mercadorias. Estas estão ali por seu valor de troca, e não por seu valor de uso, possuindo, por si, um sistema semiológico anterior, composto por significante e significado, os quais, combinados, geram um signo. A fantasmagoria torna-as, para o trabalhador (a primeira clientela de tais exposições), algo que extrapola seu sentido original. A fantasmagoria enquanto mito insere tais mercadorias em um segundo sistema semiológico, no qual seu sentido inicial é suprimido (seu uso, por exemplo, ou seu valor decorativo) e deformado. A mercadoria passa, então, a ser apenas forma. A ela é atribuído um conceito, como seu caráter de inovação, ou ainda a identificação que elas podem proporcionar aos espaços privados do homem burguês, que como afirma Benjamin, ao comentar sobre Luis Felippe ou os intérieur, anseia por deixar seus rastros em algum lugar, por marcar sua vivência (2006, p. 60). Juntamente com a forma anterior, esse conceito resulta em uma significação final, que, para Barthes, "tem como função deformar" (1993, p. 162). A mercadoria, então, ao ser cooptada pelo mito da fantasmagoria, admite, para seu comprador, uma significação deformada.

Ao comentar sobre as exposições universais, Benjamin utiliza uma frase de Alphonse Toussenel para referir-se à sedução que as mercadorias exercem sobre os consumidores: "Não há prazer maior para o leão que o de lhe cortarem as unhas, contanto que uma moça bonita segure a tesoura". (TOUSSENEL, 1859, p. 20 apud. BENJAMIN, 2006, p. 58) A frase é interessante por fazer clara referência ao comportamento do consumidor em tais exposições, que não percebe sua própria exploração, pois tem a ilusão de que dela rende um fruto belo. Nesse sentido, acredito que a fantasmagoria funcione como um típico produto da sociedade burguesa, que, como afirma Barthes, "é o campo privilegiado das significações míticas" (1993, p. 58.). O mito serviria, portanto, para a manutenção de determinadas estruturas, pois ao se apropriar de elementos pré-existentes e deformar sua significação, ele devolveria àquilo que extrai do real não a própria realidade, mas uma imagem naturalizada do real, pensando aqui juntamente a Barthes.

O pensamento de Barthes sobre o mito aproxima-se ainda mais da noção de fantasmagoria benjaminiana quando afirma que "o mito é constituído pela eliminação da qualidade histórica das coisas: nele, as coisas perdem a lembrança da sua produção" (BARTHES, 1993, p. 163). A significação que os mitos atribuem às linguagens que mitificam encobre não só o sentido inicial dessas linguagens, mas também retira delas seu caráter histórico, político, em um processo idêntico ao realizado pelas fantasmagorias, já que, para que um trabalhador se sinta impelido à compra de uma mercadoria (não por seu valor de uso), é necessário que ele esqueça que ele mesmo a produziu, e que ceder a seu charme seria nada mais que alimentar um processo cíclico sem sentido ou benefício aparente.

\section{Considerações Finais}

A forma através da qual Walter Benjamin vê as manifestações culturais e sociais da modernidade como fantasmagorias mostra que aí opera um processo mitológico semelhante ao processo através do qual Barthes analisa os diversos produtos culturais da França que lhe 
foi contemporânea. Em sua operação de mitólogo - que Barthes define como aquele que decifra o mito e compreende sua deformação (BARTHES, 1993, p. 149) -, Benjamin observa que a modernidade está inserida em um universo fantasmagórico, de ilusão, de imagens de uma realidade deformada, que não corresponde necessariamente ao real.

$\mathrm{O}$ século XIX não soube responder às inovações tecnológicas com uma nova ordem social, e, por isso, recorre a mediações ilusórias que buscam manter viva a proposta da modernidade: a inovação, o choque entre o antigo e o novo. É importante ressaltar, ainda, que a fantasmagoria não está sendo associada aqui à noção de mito por ser interpretada como uma "mentira" da modernidade, e sim porque ela reelabora as significações e as mediações entre os homens e as coisas, faz com que a um sistema de signos anteriores novos sentidos sejam atribuídos e, assim, permite que o novo continue sendo aquilo que se busca nessa sociedade moderna.

Já o desmonte semiológico de Barthes, que se volta para obras literárias, artistas de cinema, escritores, e até mesmo para propagandas de sabão em pó, margarina e brinquedos infantis, tem a intenção de desvelar a naturalização de certos aspectos e modos de vida como um mito que serve a uma inversão ideológica que definiria a burguesia. É ele quem afirma: $\mathrm{O}$ mito não nega as coisas; a sua função é, pelo contrário, falar delas; simplesmente, purifica-as, inocenta-as, fundamenta-as em natureza e em eternidade, dá-lhes uma clareza, não de explicação, mas de constatação." (1993, p. 163). É nesse sentido que Barthes afirma que "o mito é uma fala despolitizada" (BARTHES,1993, p. 163).

Por fim, acredito que Benjamin e Barthes, em relação às suas formas de desmontar os produtos culturais das sociedades francesas em distintos períodos, guardem entre si inúmeras diferenças. Porém, também acredito que ambos guardem entre si uma importante semelhança resultante desses dois estudos: a percepção de que, à ausência de uma inovação na ordem social, a cultura responde com mitos que tentam mascarar a permanência da ordem social antiga.

\section{Referências Bibliográficas}

ARENDT, H. Homens em Tempos Sombrios. São Paulo: Companhia das Letras, 1987.

BARTHES, R. Mitologias. Rio de Janeiro: Editora Bertrand do Brasil S.A., 1993.

BENJAMIN, W. "Paris, Capital do Século XIX <Exposé de 1939>”. In: Passagens. Belo Horizonte: Editora UFMG, 2006.

Passagens. Belo Horizonte: Editora UFMG, 2006.

BOLLE, W. Fisiognomia da Metrópole Moderna. São Paulo: Edusp, 1994. 
